\title{
Erratum to: 3D Finite Element Modelling of Cutting Forces in Drilling Fibre Metal Laminates and Experimental Hole Quality Analysis
}

\author{
Khaled Giasin ${ }^{1} \cdot$ Sabino Ayvar-Soberanis ${ }^{2}$. \\ ${\text { Toby } \text { French }^{3} \cdot \text { Vaibhav Phadnis }}^{2}$
}

Published online: 26 August 2016

(C) Springer Science+Business Media Dordrecht 2016

\section{Erratum to: Appl Compos Mater \\ DOI 10.1007/s10443-016-9517-0}

The original version of this article, unfortunately, contained an error. The captured image for Fig. 2 was incorrect. The correct image is given in this article and the original version was updated to reflect the correct figure.

The online version of the original article can be found at http://dx.doi.org/10.1007/s10443-016-9517-0

Khaled Giasin

meq11kg@sheffield.ac.uk

1 Composite Systems Innovation Centre, Department of Mechanical Engineering, The University of Sheffield, Sir Frederick Mappin Building, Mappin Street, Sheffield S1 3JD, UK

2 Advanced Manufacturing Research Centre with Boeing, The University of Sheffield, Advanced Manufacturing Park, Wallis Way, Catcliffe, Rotherham S60 5TZ, UK

326 Grenadine Way, Tring, Hertfordshire HP23 5EA, UK 


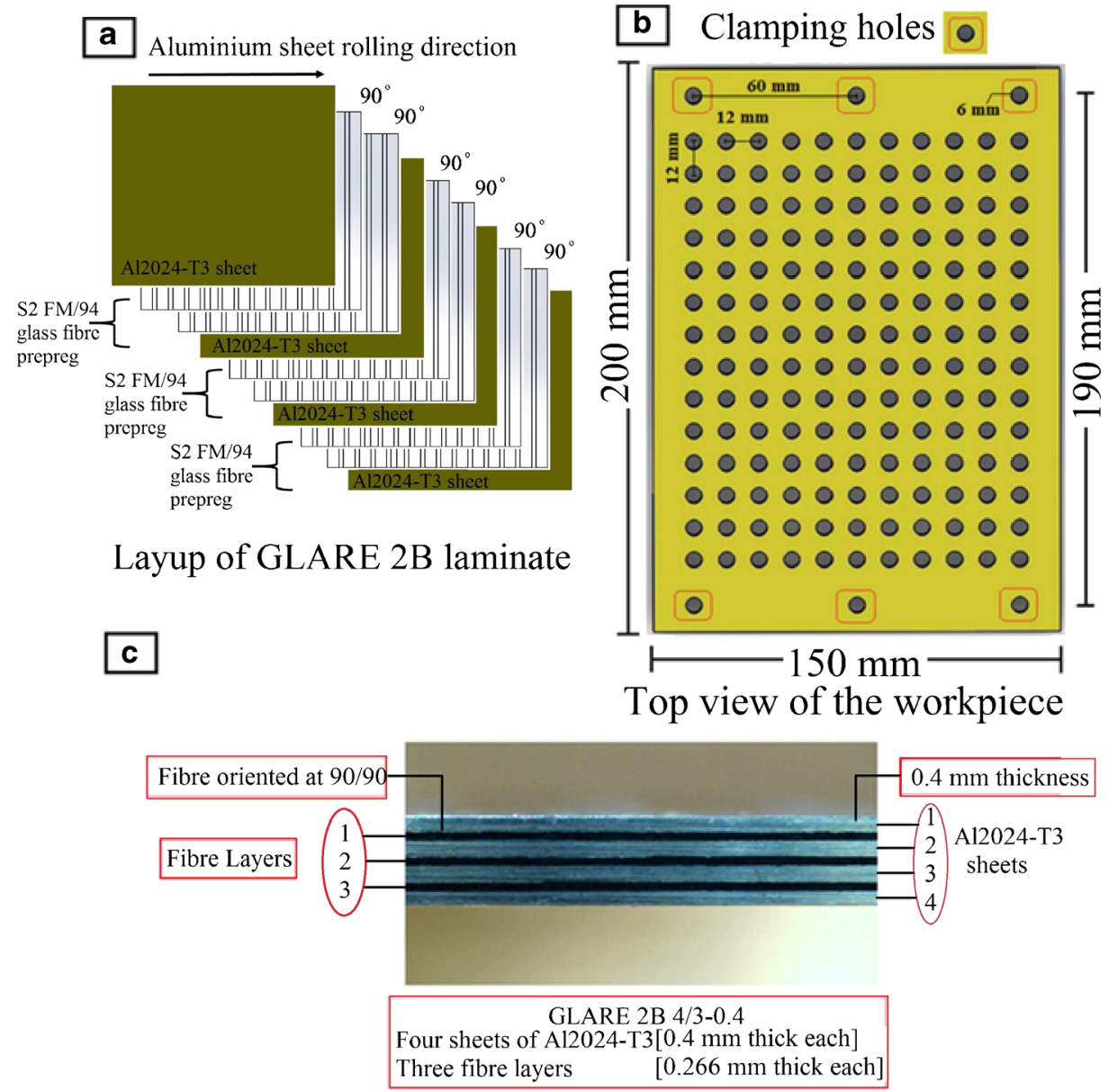

Fig. 2 Details of GLARE 2B-4/3-0.4 workpiece used for the drilling trials a Layup of GLARE 2B laminate b Top view of GLARE laminate [19] c Side view of GLARE 2B 4/3 laminate 